\title{
A Study of the Cytotoxicity of a New Nonwoven Polymeric Fibrous Bandaging Material in Vitro
}

\author{
Alexander M. Dygai ${ }^{1}$, Ludmila M. Ogorodova ${ }^{2}$, Sergey G. Psakhie ${ }^{3}$, Yuri P. Belsky ${ }^{1}$, Natalia V. Belska ${ }^{1}$, \\ Marina G. Danilets ${ }^{1 *}$, Anastasia A. Ligatcheva ${ }^{1}$, Alexey A. Churin ${ }^{1}$
}

${ }^{1}$ Research Institute of Pharmacology, Siberian Branch of the Russian Academy of Medical Sciences, Tomsk, Russia; ${ }^{2}$ Siberian State Medical University, Tomsk, Russia; ${ }^{3}$ Institute of Strength Physics and Materials Science, Siberian Branch of Russian Academy of Sciences, Tomsk, Russia.

Email: *m.danilets@mail.ru

Received March 24 ${ }^{\text {th }}, 2011$; revised April 25 $5^{\text {th }} 2011$; accepted May 10 ${ }^{\text {th }}, 2011$.

\begin{abstract}
Traditionally used cotton-based bandaging materials have several disadvantages which can be overcome by using another fabric structure - nonwoven fabric. Moreover, these materials are more spongeous which increases their sorption capacity. The new bandaging material developed by the Institute of Physics of Strength and Material Science of the Siberian Branch of the Russian Academy of Sciences has even better sorption capacity with improved sorption properties. Its sorption capacity has been increased by means of an additional introduction of porous aluminum hydrate particles into fabric. It is important that a bandaging material has a good biocompatibility and does not have any cytotoxic effect on cells and tissues. Here it is present results of the study of the material's direct contact and indirect cytotoxicity assays in comparison with cotton gauze. It have found that in the direct contact of nonwoven polymeric fibrous bandaging material (NPFBM) with cells for 24 hours of cultivation no changes in cell morphology take place, nor does the amount of dead cells increase. These conclusions have been made by means of both a visual examination and an MTT assay. The NPFBM extract did not have any cytotoxic effect on the tested cells either. The obtained results allow us to make a conclusion that the NPFBM complies with the international standard ISO 10993-5, which is applied to medical goods, and can from now on be applied in the treatment of infected wounds in clinical practice.
\end{abstract}

Keywords: Cytotoxicity, Bandaging Materials, Development of Biocompatible Biomaterials

\section{Introduction}

Modern bandaging materials must meet certain requirements, including good absorbing and sorption capacity in order to absorb and keep exudates, capture and securely isolate pathogenic microorganisms and, at the same time, to prevent microorganisms from getting into the wound [1]. Gauze has been used mostly in local wound care until now, mainly because of its low price and accessibility [2]. There is a variety of products that control processes of wound healing and which are produced with use of polymers such as hydrocolloids, alginate, chitin and so on [3-5]. Some of products possess an antimicrobial properties and contain antiseptics (iodine, polyhexamethylene biguanide, silver) [5,6]. These dressings vary by compounds content of antiseptics and dressing component such as nylon, mesh, hydrocolloid or methylcellulose. Silver as antimicrobial component is most occurring metal of wound dressings materials. In our opinion alu- minium hydrate is such antimicrobial component in a dressing material which we investigated.

Nonwoven fabric of 1 - $3 \mu \mathrm{m}$ diameter has a more developed surface and a more porous structure than materials of thicker fiber, which renders this fabric the ability to absorb quicker and keep the absorbed liquid better. We have produced a nonwoven polymeric fibrous bandaging material (NPFBM). This material can absorb and retain the absorbed liquid due to an additional introduction of porous particles of aluminum hydrate into the fabric. Moreover, the aluminum hydrate particles produced from electroexplosive aluminium nanopowders have a high sorption capacity due to their hydrophilic properties and a high specific surface area. In the course of previously conducted research, we have been discovered the NPFBM's wound healing and antibacterial properties. In this research, the non-organic nanofibers of aluminium oxide-hydroxide phases were applied on polymeric acetylcellulose fibers. It was discovered that this material re- 
duces the wound healing period and significantly accelerates sanitation of infected injuries, influencing positively the angiogenesis process, making positive influence on regeneration processes in damaged tissues [7]. It hadn't toxic effect on experimental animals [7]. In this connection, the purpose of the current research is the examination of compliance of the studied material with international standards for medical goods and investigation of new bandaging material cytotoxicity using in vitro methods [8].

\section{Materials and Methods}

\subsection{Sample Preparation and Its Characteristics}

The nonwoven polymeric fibrous bandaging material (NPFBM) is produced on the basis of nonwoven microfibrous fabric made of a biologically inert polymer-cellulose acetate - by means of electroforming in the Institute of Physics of Strength and Material Science, the Siberian Branch of the Russian Academy of Sciences, Tomsk. The fine particles of aluminum hydrate, derived from electroexplosive aluminium nanopowders $0.2-5.0$ $\mathrm{nm}$ in size, with specific surface area $100-250 \mathrm{~m}^{2} / \mathrm{g}$ and $50 \%-95 \%$ porosity, are fixed on microfibers.

\subsection{Cells and Cell Culture}

Two mouse cell lines (P-815, L-929) and one human cell line (K-562) were used. The cells were cultured in a culture medium containing RPMI 1640 (Sigma), 10\% fetal bovine serum (Hyclone), $2 \mathrm{mM}$ L-glutamine (Sigma), 10 mM HEPES (Serva), 0.05 mM 2-mercaptoethanol (Fluka) and $50 \mu \mathrm{g} / \mathrm{ml}$ gentamycin (Sigma).

\subsection{Direct Contact Cytotoxicity Assay [8]}

The cell culture incubation was carried out in the direct contact with the NPFBM. Samples were compared with nulls and with positive and negative controls. As the positive control, we used $0.1 \%$ and $1 \%$ phenol solution (a highly purified material distilled with argon). We used cotton gauze as the negative control (Marketing Authorization Ministry of Public Health of Russia No. 01012005/12161-05; State Standard 1172-93). Cells were incubated in a 24 -well plate at a density of $2 \times 10^{5}$ cells $/ \mathrm{ml}$, at $37^{\circ} \mathrm{C}$ (Costar, Corning Incorporated, Corning, $\mathrm{NY}$ ) for $24 \mathrm{~h}$ in a $5 \% \mathrm{CO}_{2}$ humidified incubator (Sanyo). The studied sample of the NPFBM was put in each well so that it took $10 \%$ of the well bottom. At the end of the incubation, the cells were collected and used for quantitative and qualitative assessment of the NPFBM's cytotoxity. For the qualitative assessment, it was used a visual cell examination with supravital staining $(0.1 \%$ trypan blue). We counted the number of viable and dead cells as well as the cells with deviations from the normal morphology (vacuolization, nuclear disintegration, cytolysis, and membrane integrity) by means of a light microscope. The results are presented as a percentage. Moreover, the L929 cells were photographed using an Olympus IX50 microscope, and the morphological changes indicating cytotoxicity and cell growth characteristics were evaluated. For the quantitative assessment of the NPFBM effect on cells, a colorimetric assay (MTT assay) was used as described earlier [9]. Briefly, $0.1 \mathrm{ml}$ of cell suspension were transferred to 96-well flatbottomed tissue culture plates (Costar, Corning Incorporated, Corning, NY), MTT (3-[4,5-dimethylthiazol-2-yl]-2,5diphenyltetrazolium bromide, Serva) was added to each well in a final concentration of $200 \mu \mathrm{g} / \mathrm{ml}$. Cells were incubated at $37^{\circ} \mathrm{C}$ in $5 \% \mathrm{CO}_{2}$ humidified incubator for 4 h. After that, MTT solution was removed and the insoluble formazan crystals were dissolved in $0.1 \mathrm{ml}$ dimethylsulfoxide (DMSO, Sigma), and the absorbance was then determined at $550 \mathrm{~nm}$, using a microplate reader (LabSystems). The results are presented in optical-density units.

\subsection{Indirect Cytotoxicity Assay [8]}

To assess cytotoxity in the indirect contact, material extracts were prepared in the following way: the NPFBM (test sample) and cotton gauze (the negative control, Marketing Authorization Ministry of Public Health of Russia No. 01012005/12161-05; State Standard 1172-93) were placed into aseptic conditions in a culture medium with a material area $\left(\mathrm{cm}^{2}\right)$ and culture medium $(\mathrm{ml})$ ratio of $6 / 1$, and incubated at $37^{\circ} \mathrm{C}$ in $5 \%$.

$\mathrm{CO}_{2}$ humidified incubator for $72 \mathrm{~h}$. After that, extractions were collected and plated $0.1 \mathrm{ml}$ each in 96-well flat-bottomed tissue culture plates (Costar, Corning Incorporated, Corning, NY), containing cells at a density of $2 \times 10^{5}$ cells/well in $0.1 \mathrm{ml}$ of the culture medium. Cells were cultured at $37^{\circ} \mathrm{C}$ for $24 \mathrm{~h}$ in a $5 \% \mathrm{CO}_{2}$ humidified incubator (Sanyo). As the null control, we used a culture medium which was influenced by the same conditions and procedures as the material extracts. For the qualitative assessment, we used a visual cell examination with supravital staining ( $0.1 \%$ trypan blue), as well as the direct contact. For the quantitative assessment of the extracts effect, 4 hours before the end of incubation, MTT was added to each well $(200 \mu \mathrm{g} / \mathrm{ml})$, and an MTT assay was carried out, as well as in direct contact.

\subsection{Data Analysis}

Statistical analysis was performed using nonparametric Mann-Whitney test. Values in tables are presented as a mean (arithmetic mean) and standard deviation. 


\section{Results}

\subsection{Direct Contact Cytotoxicity}

The visual examination has shown that the NPFBM cultivation in a direct contact with cells does not cause any increase of the amount of dead cells of the studied lines (Table 1). Phenol displays a dose-dependent cytotoxicity action. A direct contact of the NPFBM with cells for 24 hours (Table 2) did not cause any increase of the percentage of cells with deviations from the normal morphology (vacuolization, nuclear disintegration, cytolysis, and membrane integrity).

Phenol solutions caused significant changes in cells morphology, the percentage of modified cells P-815 was increasing along with the increasing of phenol concentration. The image of L929 cells after a 24-hour cultivation with the NPFBM and phenol solutions are represented in Figure 1.

The NPFBM (Figure 1(b)) showed a good biocompatibility, i.e. there was no cytotoxicity in relation to L929 cells, when compared with intact, control cell culture (Figure 1(a)). As shown in Figure 1, phenol 0.1\% (Figure 1(c)) had a moderate toxic effect, while phenol $1 \%$ appeared moderately cytotoxic, causing changes in the cell morphology and the decrease of the density of viable cells (Figure 1(d)).

According to the MTT assay results, the NPFBM and cotton gauze after a direct contact with cells for 24 hours did not have any cytotoxic effect (Table 3). Phenol solutions had a significant cytotoxic effect in both the applied concentrations.

\subsection{Indirect Cytotoxicity}

The results of studying the NPFBM extracts effect on cell viability are presented in Table 4 . The NPFBM extract did not have any cytotoxic effect on any cell lines in all the studied dilutions $(1 / 2,1 / 4,1 / 8,1 / 16)$. The cotton gauze extract decreased the amount of viable P-815 cells in $1 / 4$ dilutions. Phenol solutions decreased the percentage

Table 1. Cell viability (\%) after a direct contact with the NPFBM.

\begin{tabular}{|c|c|c|}
\hline \multirow{2}{*}{ Treatment } & \multicolumn{2}{|c|}{ Cell line } \\
\hline & P-815 & $\mathrm{K}-562$ \\
\hline Medium alone (null control) & $94.03 \pm 10.77$ & $97.88 \pm 0.55$ \\
\hline Cotton gauze (negative control) & $93.78 \pm 11.58$ & $97.61 \pm 0.71$ \\
\hline NPFBM & $96.98 \pm 13.25$ & $96.82 \pm 1.57$ \\
\hline Phenol 0.1\% (positive control) & $33.81 \pm 12.62 *$ & $13.90 \pm 1.46^{*}$ \\
\hline Phenol 1\% (positive control) & $7.75 \pm 12.04 *$ & $7.06 \pm 2.34^{*}$ \\
\hline
\end{tabular}

Values are the mean \pm S.D. $(N=4),{ }^{*} p<0.05$ versus null control.
Table 2. The number of cells with changes in cellular morphology (\%) after a direct contact with NPFBM.

\begin{tabular}{|c|c|c|}
\hline \multirow{2}{*}{ Treatment } & \multicolumn{2}{|c|}{ Cell line } \\
\hline & P-815 & K-562 \\
\hline Medium alone (null control) & $19.37 \pm 14.60$ & $7.68 \pm 1.47$ \\
\hline Cotton gauze (negative control) & $23.73 \pm 12.83$ & $7.99 \pm 2.25$ \\
\hline NPFBM & $16.57 \pm 12.22$ & $6.22 \pm 1.61$ \\
\hline Phenol $0.1 \%$ (positive control) & $74.26 \pm 13.69^{*}$ & $91.61 \pm 3.27 *$ \\
\hline Phenol 1\% (positive control) & $97.35 \pm 11.33 *$ & $98.33 \pm 1.67 *$ \\
\hline
\end{tabular}

Values are the mean \pm S.D. $(N=4),{ }^{*} p<0.05$ versus null control.

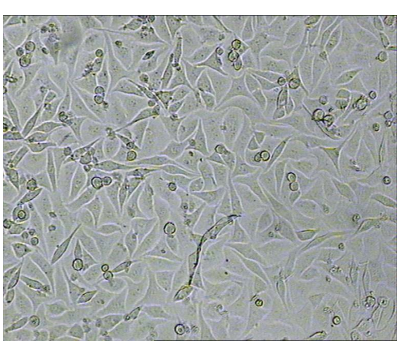

(a)

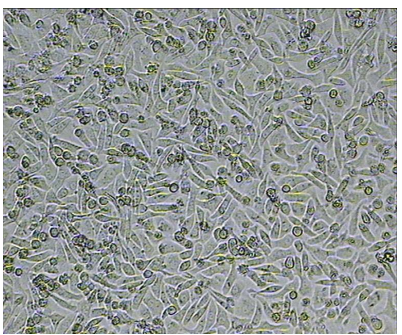

(c)

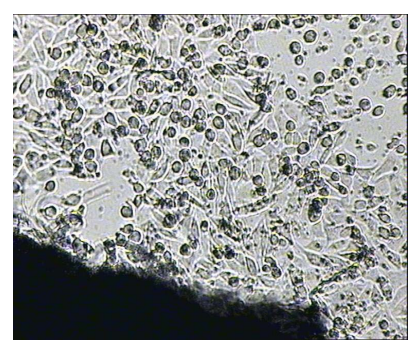

(b)

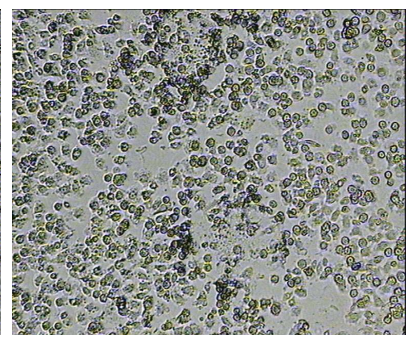

(d)
Figure 1. The biocompatibility of the NPFBM in the L929 cells culture (direct contact), no staining, magnification $140 \times$. (a) Control cell culture; (b) NPFBM, an NPFBM fragment and aluminum hydrate particles released from the NPFBM are shown in the lower part of the picture; (c) Phenol solution $0.1 \%$ and (d) Phenol solution $1 \%$.

Table 3. The cytotoxicity of the NPFBM assessed by MTT assays (optical density).

\begin{tabular}{lcc}
\hline \multirow{2}{*}{ Treatment } & \multicolumn{2}{c}{ Cell line } \\
\cline { 2 - 3 } & P-815 & K-562 \\
\hline Medium alone (null control) & $550 \pm 17$ & $395 \pm 29$ \\
Cotton gauze (negative control) & $493 \pm 25$ & $393 \pm 11$ \\
NPFBM & $517 \pm 41$ & $401 \pm 16$ \\
Phenol 0.1\% (positive control) & $142 \pm 15^{*}$ & $108 \pm 6^{*}$ \\
Phenol 1\% (positive control) & $83 \pm 4^{*}$ & $90 \pm 4^{*}$ \\
\hline
\end{tabular}

Values are the mean \pm S.D. $(N=5),{ }^{*} p<0.05$ versus null control. 
Table 4. Effects of the NPFBM extracts on cell viability (\%).

\begin{tabular}{lcc}
\hline \multirow{2}{*}{ Treatment } & \multicolumn{2}{c}{ Cell line } \\
\cline { 2 - 3 } & P-815 & K-562 \\
\hline Medium alone (null control) & $98.73 \pm 0.58$ & $97.64 \pm 0.66$ \\
Cotton gauze extract 1/2 diluted & $96.71 \pm 0.65$ & $95.83 \pm 0.83$ \\
Cotton gauze extract 1/4 diluted & $95.67 \pm 0.26^{*}$ & $98.33 \pm 0.83$ \\
Cotton gauze extract 1/8 diluted & $96.61 \pm 0.83$ & $97.08 \pm 0.62$ \\
Cotton gauze extract 1/16 diluted & $97.61 \pm 0.65$ & ND \\
NPFBM extract 1/2 diluted & $97.17 \pm 1.15$ & $95.63 \pm 0.68$ \\
NPFBM extract 1/4 diluted & $96.25 \pm 1.68$ & $97.44 \pm 0.52$ \\
NPFBM extract 1/8 diluted & $97.72 \pm 0.69$ & $97.08 \pm 1.25$ \\
NPFBM extract 1/16 diluted & $97.45 \pm 0.53$ & ND \\
Phenol 0.1\% (positive control) & $44.95 \pm 11.31^{*}$ & $38.59 \pm 7.45^{*}$ \\
Phenol 1\% (positive control) & $14.01 \pm 5.34^{*}$ & $4.46 \pm 0.95^{*}$ \\
\hline
\end{tabular}

Values are the mean \pm S.D. $(N=4), \mathrm{ND}-$ value not determined, $* p<0.05$ versus null control.

of P-815 and K-562 viable cells, depending on the dosage.

The results of studying the extracts effect on cellular morphology are presented in Table 5. The morphology of cells cultivated with different dilutions of the studied NPFBM extracts and cotton gauze did not change. Phenol solutions increased the percentage of deviated cellular morphology.

The results of studying cytotoxic effects of the NPFBM extracts in MTT assays are presented in Table 6.

The NPFBM and cotton gauze extracts did not have any cytotoxic effect on P-815 and K-562 line cells. Statistically significant decrease in $\mathrm{P}-815$ cell viability presented in Table 4 probably was not a true toxic effect. It proves by absence of changes in other dilution. The cotton gauze extract in $1 / 2$ and $1 / 4$ dilution had a cytotoxic effect on L-929 line cells. Phenol solutions had a clearly marked cytotoxic effect on P-815 and K-562 line cells both in high and in low concentrations.

\section{Discussion}

We have shown that the direct contact of the NPFBM with cells during a 24-hour cultivation period did not cause any changes in cellular morphology and did not cause any increase of the amount of dead cells upon a visual examination. MTT assays did not reveal any cytotoxic effect of the NPFBM either. The cotton gauze used as negative control showed the same results. Therefore,
Table 5. Effects of NPFBM extracts on the number of cell with changes in morphology $(\%)(\mathrm{X} \pm \mathrm{m})$.

\begin{tabular}{lcc}
\hline \multirow{2}{*}{ Treatment } & \multicolumn{2}{c}{ Cell line } \\
\cline { 2 - 3 } & P-815 & K-562 \\
\hline Medium alone (null control) & $11.61 \pm 0.81$ & $8.23 \pm 1.36$ \\
Cotton gauze extract 1/2 diluted & $8.61 \pm 1.46$ & $10.29 \pm 2.23$ \\
Cotton gauze extract 1/4 diluted & $9.33 \pm 1.05$ & $7.84 \pm 0.63$ \\
Cotton gauze extract 1/8 diluted & $6.48 \pm 2.18$ & $10.00 \pm 1.67$ \\
Cotton gauze extract 1/16 diluted & $7.66 \pm 1.69$ & ND \\
NPFBM extract 1/2 diluted & $10.83 \pm 1.20$ & $10.83 \pm 2.50$ \\
NPFBM extract 1/4 diluted & $11.33 \pm 2.01$ & $10.42 \pm 1.46$ \\
NPFBM extract 1/8 diluted & $8.12 \pm 1.26$ & $7.92 \pm 2.71$ \\
NPFBM extract 1/16 diluted & $6.11 \pm 0.34$ & ND \\
Phenol 0.1\% (positive control) & $67.72 \pm 9.66^{*}$ & $70.47 \pm 4.23^{*}$ \\
Phenol 1\% (positive control) & $88.52 \pm 5.74 *$ & $98.79 \pm 1.21^{*}$ \\
\hline
\end{tabular}

Values are the mean \pm S.D. $(N=4), \mathrm{ND}-$ value not determined, ${ }^{*} p<0.05$ versus null control.

Table 6. Cytotoxicity of NPFBM extracts assessed by MTT assays (optical density).

\begin{tabular}{lccc}
\hline \multirow{2}{*}{ Treatment } & \multicolumn{3}{c}{ Cell line } \\
\cline { 2 - 4 } & P-815 & K-562 & L-929 \\
\hline Medium alone (null control) & $891 \pm 35$ & $455 \pm 29$ & $713 \pm 29$ \\
Cotton gauze extract 1/2 diluted & $783 \pm 50$ & $558 \pm 45$ & $545 \pm 65^{*}$ \\
Cotton gauze extract 1/4 diluted & $841 \pm 16$ & $492 \pm 32$ & $577 \pm 27^{*}$ \\
Cotton gauze extract 1/8 diluted & $858 \pm 27$ & $450 \pm 13$ & $667 \pm 23$ \\
Cotton gauze extract 1/16 diluted & $992 \pm 27$ & ND & $656 \pm 32$ \\
NPFBM extract 1/2 diluted & $981 \pm 101$ & $433 \pm 26$ & $688 \pm 49$ \\
NPFBM extract 1/4 diluted & $1009 \pm 49$ & $454 \pm 41$ & $762 \pm 74$ \\
NPFBM extract 1/8 diluted & $988 \pm 35$ & $401 \pm 19$ & $667 \pm 35$ \\
NPFBM extract 1/16 diluted & $986 \pm 28$ & ND & $684 \pm 34$ \\
Phenol 0.1\% (positive control) & $142 \pm 15^{*}$ & $163 \pm 17^{*}$ & ND \\
Phenol 1\% (positive control) & $83 \pm 4^{*}$ & $97 \pm 5^{*}$ & ND \\
\hline
\end{tabular}

Values are the mean \pm S.D. $(N=4), \mathrm{ND}-$ value not determined, ${ }^{*} p<0.05$ versus null control.

the NPFBM has the same biological safety as the cotton gauze used widely for injured tissues protection. The NPFBM extract did not have any cytotoxic effect on the tested cells either. However, cotton gauze extract in high concentrations could have a harmful effect on tested cells, although it did not influence their morphology much. 
This may be as a result of technological peculiarities of cotton gauze processing which is carried out with the use of some chemical agents. Residual quantities of these agents could cause the negative effects observed. The new bandaging material NPFBM does not have this kind of drawback. In conclusion, the new nonwoven polymeric fibrous bandaging material has a good biocompatibility and does not have any cytotoxic effect after a direct contact with the cell culture. Unlike cotton gauze, the NPFBM does not contain any additives that could have an adverse effect on the cell culture through extractive additives. The obtained results allow us to draw a conclusion that the NPFBM complies with the ISO 10993-5, which is applied to medical goods, and can from now on be applied to treating infected wounds in clinical practice.

\section{Conclusions}

The present work demonstrates the results of study of the NPFBM's direct contact and indirect cytotoxicity assays in comparison with cotton gauze according to the main principles of international standard ISO 10993-5. It has been shown that the NPFBM extract had not any cytotoxic effect on the tested cells. Thus, these NPFBM produced with the use of nanotechnology may be used for health care purpose like safe and nontoxic wound healing bandaging material.

\section{REFERENCES}

[1] T. D. Turner, "Hospital Usage of Absorbent Dressings," Pharmaceutical Journal, Vol. 222, 1979, pp. 421-424.
[2] V. J. Jones, "The Use of Gauze: Will It Ever Change?" International Wound Journal, Vol. 3, No. 2, 2006, pp. 79-88. doi:10.1111/j.1742-4801.2006.00215.X

[3] X. Wang, Y. Yan and R. Zhang "A Comparison of Chitosan and Collagen Sponges as Hemostatic Dressings," Journal of Bioactive and Compatible Polymers, Vol. 21, No. 1, 2006, pp. 39-54. doi:10.1177/0883911506060201

[4] G. Chaby, P. Senet, M. Vaneau, et al. "Dressings for Acute and Chronic Wounds," Archives of Dermatology, Vol. 143, No. 10, 2007, pp. 1297-1304.

doi:10.1001/archderm.143.10.1297

[5] T. S. Stashak, E. Farstvedt and A. Othic "Update on Wound Dressings: Indications and Best Use," Clinical Techniques in Equine Practice, Vol. 3, No. 2, 2004, pp. 148-163. doi:10.1053/j.ctep.2004.08.006

[6] M. Ip, S. L. Lui, V. Poon, et al., "Antimicrobial Activities of Silver Dressings: An in Vitro Comparison," Journal of Medical Microbiology, Vol. 55, No. 1, 2006, pp. 59-63. doi:10.1099/jmm.0.46124-0

[7] A. M. Dygaj, M. I. Lerner, V. V. Novitsky, L. M. Ogorodova, S. G. Psakhie and A. A. Churin "The Nonwoven Material of Medical Appointment Possessing Wound Healing, Antibacterial and Antiviral Activity and Bandaging Material on its Basis," Patent (RU) N 2397781 from 27.08.2010, (in Russian).

[8] ISO 10993-5, "Biological Evaluation of Medical Devices, Part 5: Tests for Cytotoxicity, in Vitro Methods," International Standardization Organisation, Geneva, 1992.

[9] T. R. Mosmann, "Rapid Colorimetric Assay for Cellular Growth and Survival: Application to Proliferation and Cytotoxicity Assays," Journal of Immunological Methods, Vol. 65, No. 1-2, 1983, pp. 55-63. doi:10.1016/0022-1759(83)90303-4 